\title{
Working memory moderates the relation between the brain-derived neurotropic factor (BDNF) and psychotherapy outcome for depression
}

Citation for published version (APA):

Bruijniks, S. J. E., van Grootheest, G., Cuijpers, P., de Kluiver, H., Vinkers, C. H., Peeters, F., Penninx, B., Teunissen, C. E., \& Huibers, M. J. H. (2020). Working memory moderates the relation between the brainderived neurotropic factor (BDNF) and psychotherapy outcome for depression. Journal of Psychiatric Research, 130, 424-432. https://doi.org/10.1016/j.jpsychires.2020.07.045

Document status and date:

Published: 01/11/2020

DOI:

10.1016/j.jpsychires.2020.07.045

Document Version:

Publisher's PDF, also known as Version of record

\section{Document license:}

Taverne

Please check the document version of this publication:

- A submitted manuscript is the version of the article upon submission and before peer-review. There can be important differences between the submitted version and the official published version of record.

People interested in the research are advised to contact the author for the final version of the publication, or visit the DOI to the publisher's website.

- The final author version and the galley proof are versions of the publication after peer review.

- The final published version features the final layout of the paper including the volume, issue and page numbers.

Link to publication

\footnotetext{
General rights rights.

- You may freely distribute the URL identifying the publication in the public portal. please follow below link for the End User Agreement:

www.umlib.nl/taverne-license

Take down policy

If you believe that this document breaches copyright please contact us at:

repository@maastrichtuniversity.nl

providing details and we will investigate your claim.
}

Copyright and moral rights for the publications made accessible in the public portal are retained by the authors and/or other copyright owners and it is a condition of accessing publications that users recognise and abide by the legal requirements associated with these

- Users may download and print one copy of any publication from the public portal for the purpose of private study or research.

- You may not further distribute the material or use it for any profit-making activity or commercial gain

If the publication is distributed under the terms of Article $25 \mathrm{fa}$ of the Dutch Copyright Act, indicated by the "Taverne" license above, 


\title{
Working memory moderates the relation between the brain-derived neurotropic factor (BDNF) and psychotherapy outcome for depression
}

\author{
Sanne J.E. Bruijniks ${ }^{\text {a,b, }}$, Gerard van Grootheest ${ }^{\text {c,e }}$, Pim Cuijpers ${ }^{\text {a }}$, Hilde de Kluiver ${ }^{\text {c, e }}$, \\ Christiaan H. Vinkers ${ }^{c, d}$, Frenk Peeters ${ }^{f}$, Brenda Penninx ${ }^{c, e}$, Charlotte E. Teunissen ${ }^{g}$, Marcus J. \\ H. Huibers ${ }^{a, h}$ \\ a Department of Clinical, Neuro and Developmental Psychology, Amsterdam Public Health Research Institute, Vrije Universiteit Amsterdam, the Netherlands \\ ${ }^{\mathrm{b}}$ Department of Clinical Psychology and Psychotherapy, University of Freiburg, Freiburg, Germany \\ ${ }^{\mathrm{c}}$ Department of Psychiatry, Amsterdam University Medical Center, Amsterdam Neuroscience, Vrije Universiteit Amsterdam, Vrije Universiteit Amsterdam \\ d Department of Anatomy and Neurosciences, Amsterdam University Medical Center, Amsterdam Neuroscience, Amsterdam, the Netherlands \\ e GGZ InGeest Specialized Mental Health Care, Amsterdam, the Netherlands \\ ${ }^{\mathrm{f}}$ Department of Clinical Psychological Science, Maastricht University, Maastricht, the Netherlands \\ ${ }^{g}$ Neurochemistry Lab, Department of Clinical Chemistry, Amsterdam University Medical Center, Vrije Universiteit, Amsterdam Neuroscience, the Netherlands \\ ${ }^{\mathrm{h}}$ Department of Psychology, University of Pennsylvania, Philadelphia, United States
}

\section{A R T I C L E I N F O}

\section{Keywords:}

Major depressive disorder (MDD)

Brain-derived neurotropic factor (BDNF)

Working memory capacity

Psychotherapy

\begin{abstract}
A B S T R A C T
Background: Insight into patient characteristics that predict response to treatment for major depressive disorder (MDD) may help to personalize treatment and improve outcomes. One mechanism that has been linked to the success of treatment for MDD is brain-derived neurotropic factor (BDNF). BDNF is implicated in learning and memory and may play a role in the effects of psychotherapy that involves changing cognitions and behaviors. In addition, only in individuals with low BDNF, low working memory capacity has been associated with increased symptoms of depression. However, the role of BDNF and working memory capacity in psychotherapy outcome is unclear. The aim of this study was to investigate the role of BDNF and its interaction with working memory capacity in psychotherapy outcomes for MDD.

Method: Adult patients with MDD were randomized to weekly or twice weekly sessions of cognitive behavioral therapy or interpersonal psychotherapy. BDNF Val66Met polymorphism (rs6265) $(n=138)$ was defined and serum BDNF was quantified before $(n=138)$ and after psychotherapy $(n=82)$.

Results: Baseline serum BDNF and the Val66Met polymorphism were not associated with outcome and associations did not differ between treatment conditions. Working memory capacity significantly moderated the relation between baseline serum BDNF and outcome: high serum BDNF at baseline was related to less depressive symptoms following psychotherapy in the presence of high working memory capacity, but not low working memory capacity.

Discussion: These findings, if replicated, might indicate that while BDNF may not be related to psychotherapy outcomes in general, they may play a role in the presence of specific learning processes such as working memory capacity.
\end{abstract}

\section{Introduction}

Depression is the leading cause of disability worldwide (World Health Organization, 2017) and although several equally effective treatments are available (Barth et al., 2013; Cuijpers et al., 2013), response rates need to be improved (Cuijpers et al., 2014; Dobson et al., 2008). Depression can be treated with pharmacological treatment, psychotherapy or the combination of both (National Institute for Health and Care Excellence, 2018), but not each treatment might be the best fit for every patient. Insight into individual patient characteristics that predict response to treatment is therefore very important to personalize and optimize treatment effectiveness (Cohen and DeRubeis, 2018; Simon and Perlis, 2010).

One factor that has been related to the success of treatment for

\footnotetext{
* Corresponding author. University of Freiburg, Engelbergerstrasse 41, 79106, Freiburg, Germany.

E-mail address: sanne.bruijniks@psychologie.uni-freiburg.de (S.J.E. Bruijniks).
} 
depression is brain-derived neurotrophic factor (BDNF) (Aldoghachi et al., 2019; Brunoni et al., 2008; Kishi et al., 2018; Molendijk et al., 2011; Notaras et al., 2015; Polyakova et al., 2015; Sen et al., 2008). BDNF is a neurotrophin that plays a beneficial role in neurogenesis and is highly expressed the hippocampus (Balaratnasingam and Janca, 2012), an area that is important for learning and memory (Burgess et al., 2002) and in the regulation of stress (Dranovsky and Hen, 2006). Because the aim of psychotherapy is to change depressogenic cognitions and behavior with techniques that may require memory and learning (Bruijniks et al., 2019; Harvey et al., 2014; Lane et al., 2015), it is possible that high levels of BDNF could be a stimulator in providing a change in cognitions and behaviors that have been related to successful outcome (Adler et al., 2015; Kanter et al., 2010; Schmidt et al., 2019). BDNF seems therefore an interesting candidate predictor for psychotherapy outcome in depression.

Some studies already investigated the relation of blood BDNF and genetic or epigenetic changes in BDNF and the effect of psychological treatments. For example, BDNF levels in serum measured before treatment was lower in patients with poor response compared to patients with good response to 10 weekly sessions of group cognitive behavioral therapy (CBT) for panic disorder (Kobayashi et al., 2005). In addition, patients that carried Met-alleles on the Val66Met polymorphism, a genetic variant of BDNF in which the Met-alleles are associated with less release of BDNF, showed lower response to 20 weekly sessions of CBT for obsessive compulsive disorder (OCD) compared to patients without Met-alleles (Fullana et al., 2012). One study into an intensive 4-week course of dialectal behavior therapy for patients with borderline personality disorders showed that those who responded to treatment showed a decrease in methylation of the BDNF gene over time (i.e., note that low methylation has been related to increased levels of BDNF; Perroud et al., 2013). In depression, a genetic variant of the BDNF (rs11030101) showed a preventive effect on deterioration in patients that did not receive treatment (Bakker et al., 2014). However, not all studies reported significant associations between serum BDNF and treatment outcomes. da Silva et al. (2018) showed that serum levels of BDNF measured in blood did not change after 16 weekly sessions of CBT for depression, while in another study BDNF measured in plasma did not predict response to 12 to 16 sessions of twice weekly IPT for depression (Koch et al., 2009). Also, the Val66Met polymorphism was not related to response in CBT for anxiety disorders (Santacana et al., 2016) or in a genome-wide meta-analysis of psychological treatment outcome for depression or anxiety (Rayner et al., 2019).

Several factors may explain these inconsistent findings. First, many studies have only small sample sizes $(n<100)$. The power to find effects in small sample sizes is limited and can easily lead to null findings as sample sizes become smaller (Brookes et al., 2004). Second, studies are heterogeneous due to differences in populations or treatments. Third, the effect of BDNF might be moderated by individual characteristics. For example, the effect of the Val66Met polymorphism on remission of depression was seen in an Asian but not Caucasian population (Zou et al., 2010). One psychological construct that might moderate the role of BDNF in psychotherapy outcomes is working memory capacity. Like BDNF, working memory capacity has shown to be lower in patients with MDD (Beevers, 2005; Snyder, 2013) and both have been related to early life stress (Goodman et al., 2019; Zhao et al., 2017). Multiple studies have supported the genetic and epigenetic link between BDNF and working memory capacity (Brooks et al., 2014; Chen et al., 2016; Wagner et al., 2018), memory performance (Azeredo et al., 2017) or attention (Mikoteit et al., 2015). In the study of Chen et al. (2016), the relation between BDNF and working memory interacted with another gene that has repeatedly been linked to working memory: the Catechol-O-methyltransferase (COMT). Results showed that in individuals who were Val homozygote for BDNF, but not in BDNF Met-carriers, COMT Val homozygote was related to higher working memory capacity.

Also, we have suggested that learning capacity (defined as the presence of neurobiological and cognitive processes related to learning, such as working memory capacity) may moderate the effects of CBT for depression (Bruijniks et al., 2019). One small study using a sample with subclinical symptoms of depression showed that in individuals with Met-alleles of the Val66Met polymorphism, but not in individuals without Met-alleles, low working memory capacity was associated with increased symptoms of depression over time (LeMoult et al., 2014). It was suggested that BDNF may increase or decrease depression through the way patients process new information (i.e., working memory capacity) (LeMoult et al., 2014). However, the study was underpowered and overall depression levels were low (LeMoult et al., 2014). Studies that investigate the direct link between BDNF, working memory and depressive outcome in a clinical sample that received psychotherapy are lacking. Investigating the hypothesis that the effect of BDNF is moderated by working memory capacity in a larger and clinical sample might increase our insight into for whom and how BDNF mechanisms affect psychotherapy outcome for depression.

Recently, we conducted a randomized trial that showed that twice weekly sessions of CBT and interpersonal psychotheray (IPT) led to more reduction in depression compared to weekly sessions (Bruijniks et al., 2015, 2019). Using the data of this trial, the aim of the present study is twofold. Our first aim was to increase insight in whether BDNF plays a role in psychotherapy for depression. We did this by investigating change in serum BDNF from pre- to posttreatment and testing the effects of baseline serum BDNF and the Val66Met polymorphism as predictors of outcome. We hypothesized that serum BDNF would increase from preto posttreatment and that lower serum BDNF and Met-Alleles in the Val66Met polymorphism would predict worse outcome. In addition, because earlier we hypothesized that twice-weekly sessions lead to better outcomes compared to weekly sessions because a higher frequency leads to better learning, reflected by a steeper increase in serum BDNF (Bruijniks et al., 2015), we exploratory tested whether the increase in serum BDNF would be quicker and larger in the group that received twice weekly compared to weekly sessions of psychotherapy and whether the prediction of outcome with serum BDNF and Met-Alleles in the Val66Met polymorphism would differ between frequency conditions. We conducted the same exploratory analyses for CBT versus IPT. Our second aim was to investigate if there would be a subset of patients showing a stronger relation between BDNF and depression. We expected that high levels of BDNF would lead to higher effects of psychotherapy, but especially in those with high working memory capacity.

\section{Methods}

\subsection{Design}

The study was conducted in context of a large randomized trial that investigated the effects of session frequency and mechanisms of change in cognitive behavioral therapy and interpersonal psychotherapy for depression (Bruijniks et al., 2015). In this study, 200 patients were randomized to once versus twice weekly sessions of CBT and IPT over 16-24 weeks up to a maximum of 20 sessions. Results showed that twice weekly sessions led to better depressive outcomes compared to weekly sessions (Bruijniks et al., 2020). Venipuncture was conducted before the start of treatment (T0, pretreatment) and 6 months (T1, posttreatment) after the start of treatment. Informed consent was signed before the start of the study. Participants were also allowed to participate in the study without participating in the venipuncture. Outcome measurements were completed at baseline, two weeks and monthly up to six months after start of treatment. For the present study, depression scores at baseline and six months after start of treatment and the baseline measurement of working memory capacity was used. Further details about the study protocol and study results can be found in Bruijniks et al. (2015) and Bruijniks et al. (2019). 


\subsection{Participants}

170 participants (85\%) signed informed consent for venipuncture at the start of the study. Patients who provided consent for venipuncture did not differ in gender $(t(198)=-0.58, p=.55)$ or age $(t(198)=$ $-0.85, p=.39$ ), but had significantly lower depression at baseline compared to patients who did not provide consent for venipuncture (no consent: $M=38.36$ ( $S D=9.69)$, consent: $M=34.05$ ( $S D=9.89)$, $(t$ $(198)=2.20, p=.03)$. BDNF serum samples were available for 138 participants at T0 and for 82 participants at T1. For 73 participants both T0 and T1 measurements were present. Patients who had BDNF rated on both time points did not differ in gender $(t(146)=0.79, p=.89)$, depression at baseline $(t(146)=-0.14, p=.88)$ or age $(t(198)=-1.75$, $p=.08$ ) from those with BDNF measured at one time point only. The Val66Met polymorphism was present for 138 participants. Please also see the flow chart in Fig. 1 for an overview of exclusion reasons per measurement.

\subsection{Measurements}

\subsubsection{Depression: Beck Depression Inventory II (BDI-II)}

Depression was measured by the Beck Depression Inventory. The BDI-II is a 21-item self-report instrument assessing depressive symptoms over the past two weeks. A score of 0-13 indicated minimal depression, 14-19 mild depression, 20-28 moderate depression and 29-63 severe depression. Reliability and validity of the BDI-II has been supported (Beck et al., 1996; Beck et al., 1988; van der Does, 2002).

\subsubsection{Working memory: $N$-back task}

The n-back task has been regarded as a measure of working memory (WM) (Braver et al., 1997). During the n-back task participants were asked if a letter on the screen matched a letter previously (1-back, 2back, 3-back) presented for $500 \mathrm{~ms}$ with an interval of $2000 \mathrm{~ms}$. First, the participants were asked to run a test trial, where they got elaborate feedback about the incorrect responses ('The previous letter was $\mathrm{X}$, this indicated you had to press the button'). Second, the participants completed a 1-back trial $(2 \mathrm{~min}$ ) and a 2-back trial (two parts of 2.5

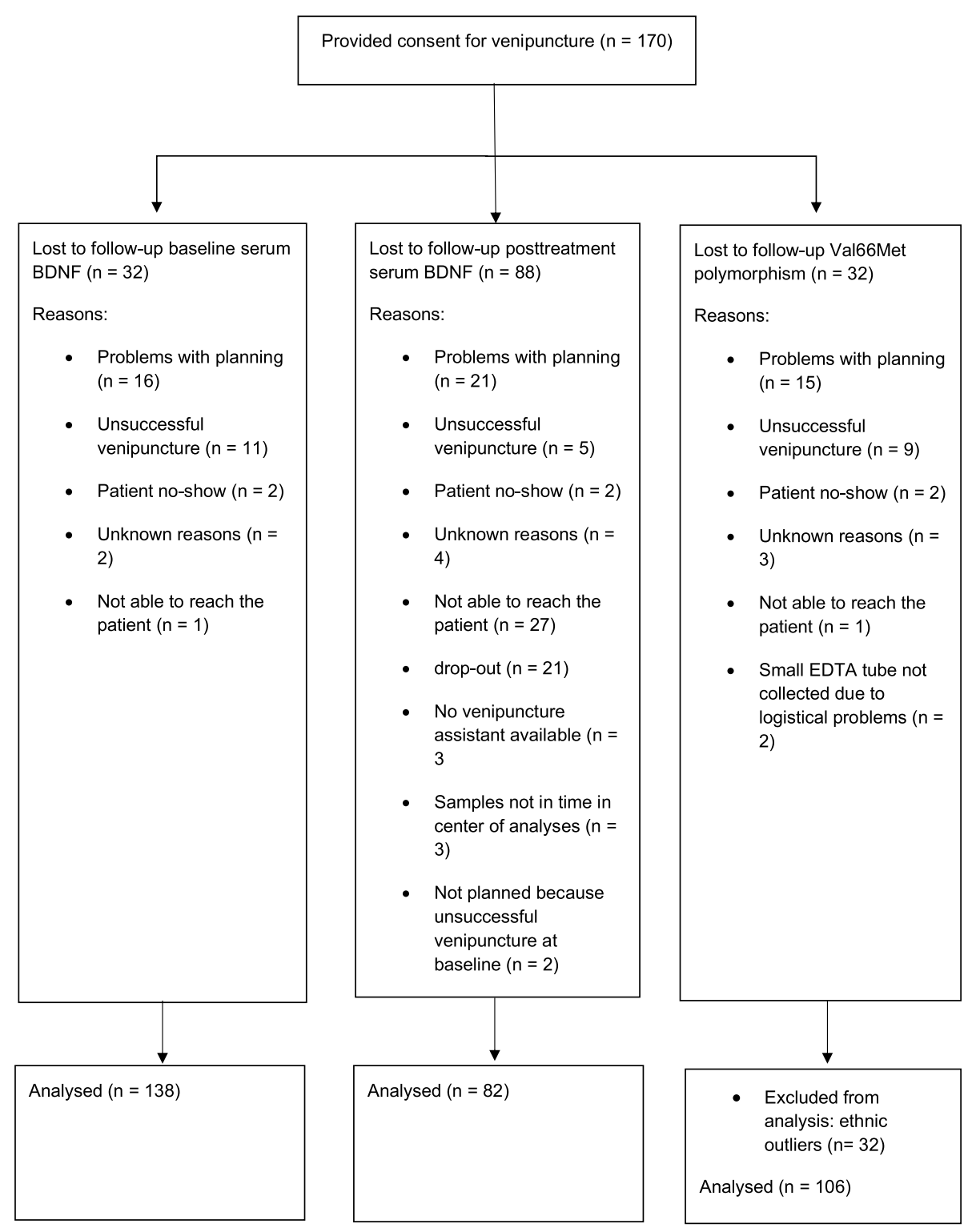

Fig. 1. Flowchart. Note that for the Val66Met polymorphism originally data was missing for 36 patients, but that for four patients blood samples at $\mathrm{T} 1 \mathrm{were}$ available and were used to determine the Val66Met polymorphism. Also note that 73 patients had measurements of T0 and T1 BDNF serum levels and a total of 150 patients had a measurement on at least one of the measurements. 
min). Only when the participants performed well on the 2-back (i.e. 2/3 correct responses; a correct response means a correct press or a correct no-press), were they forwarded to the 3-back part of the task that also took $5 \mathrm{~min}$ (two parts of $2.5 \mathrm{~min}$ ). The amount of n-backs (i.e. potential hits) in each condition was $33 \%$. Feedback was given after a correct response (marked by a green $\mathrm{V}$ ) or a miss (marked by a black X). WM load increased as the task progressed from 1-back to 3-back. The task took a maximum of $12.5 \mathrm{~min}$ and was completed at baseline. Accuracy of responses (total of correct hits (\% correctly identified n-backs) and correct no hits (\% correctly identified no presence of a n-back)) was measured and used as an outcome measure. Maximum score for each trial was 200, making the maximum score on all trials 1000 (results of the test trial were not included). Subsequently, the relative score was computed by individual score $/ 1000 * 100$.

\subsubsection{Blood sampling}

Blood samples $(2 \times 3 \mathrm{ml}$ EDTA, $1 \times$ serum tube $)$ were collected at baseline and after six months by a research assistant at the patient's home. After the venipuncture, serum samples were stored in the hospital nearby the mental health centre (i.e., VU Medical Centre for samples from GGZ inGeest, PsyQ Amsterdam and PsyQ Haarlem, Leids University Medical Centre for samples from PsyQ Leiden, Maastricht University Medical Centre for samples from Riagg Maastricht, Utrecht Medical Centre for samples from Altrecht, Radboud Medical Centre for samples from Pro Persona and GGZ Oss, Lab West (Medical Centre) for samples from PsyQ The Hague). Serum was centrifuged for $10 \mathrm{~min}$ on $1800 \mathrm{~g}$ at room temperature $\left(20^{\circ} \mathrm{C}\right)$, aliquoted into $0.5 \mathrm{ml}$ samples and stored at $80^{\circ} \mathrm{C}$. The EDTA tubes from each research site were sent to VUmc where DNA was isolated using magnetic separation (PerkinElmer, U.S.A.) and stored at $-20^{\circ} \mathrm{C}$.

\subsubsection{Serum BDNF}

Prior to analysis, serum samples were thawed at room temperature, shortly vortexed and subsequently centrifuged at $10,000 \times g$ for $10 \mathrm{~min}$. BDNF levels were measured using the commercially available and in house analytically validated BDNF Discovery Kit (Quanterix, USA) on board of the highly sensitive automated SIMOA HD-1 analyzer (Quanterix, USA). Samples were analyzed in duplicates, according to manufacturer's instructions. Different time point per patients were analyzed within one plate. The mean coefficient of variation of the duplicate measurements was $2,8 \%$ (range $0-13 \%$ ).

\subsubsection{Genotyping}

The 138 participants were genotyped with the Global Screening Array-24 v.1.0 (GSA) from Illumina (Human Genomics Facility, Erasmus MC, Rotterdam, the Netherlands). Quality control was performed with the RICOPILI pipeline developed by the Psychiatric Genomic Consortium (Lam et al., 2019). For instance, duplicate samples, samples with sex mismatches, excess heterozygosity, and call rate were removed. Single genetic variants with a low $(<0.98)$ call rate, minor allele frequency $(<0.01)$ and violated the Hardy-Weinberg equilibrium $(p<$ $10^{-6}$ ) were removed. The Val66Met polymorphism was not excluded in our sample after single variant QC thresholds were applied. Ancestry was determined based on principle component analysis. After quality control, missing data was imputed based on samples from the 1000 Genomes Project ("International Genome Sample Resource (IGSR)," 2019; The 1000 Genomes Project Consortium, 2012) as reference panel. The analyses of the Val66Met polymorphism (rs6265, position chr11:27658369) controlled for ethnic variety by excluding non-European participants ( $n=32$; U.S. National Library of Medicine, 2019), leading to $n=106$ patients for whom the Val66Met polymorphism was used in the analysis.

\subsection{Statistical analyses}

First, demographics and descriptives for each measurement were provided. Pearson correlations between baseline serum BDNF and preand posttreatment depression were calculated. Differences between responders and non-responders in serum BDNF and the presence of Met alleles in the Val66Met polymorphism were tested using an independent $t$-test and a chi-square test, respectively. Following cut-off scores for defining outcomes on the BDI-II in psychotherapy for depression (Riedel et al., 2010), response was defined as a drop of $\geq 47 \%$ points on the BDI-II from baseline to posttreatment.

Second, we analyzed changes in serum BDNF and investigated baseline serum BDNF and the Val66Met polymorphism as a predictor of treatment outcome of MDD (BDI-II score at month 6). Change in serum BDNF during treatment was conducted with a repeated measure ANOVA with baseline BDI-II as a covariate. Exploratory analyses were conducted by adding frequency condition and treatment modality as a between factor in two separate analyses and investigating the interaction with change in BDNF. To investigate whether serum BDNF or the Val66Met polymorphism predicted outcome, multiple regression analyses were conducted with the BDI-II score at posttreatment as dependent variable, and serum BDNF at baseline or the Val66Met polymorphism $(0=\mathrm{Val} /$ Val, $1=$ Val/Met, $2=$ Met/Met) as the independent variable. Because previous studies indicated that gender, age, use of antidepressants, season of sampling, time of withdrawal, haven eaten prior to blood withdrawal (fasting status), and storage duration of the samples may have an influence on serum BDNF (Bus et al., 2011; Molendijk et al., 2012; Ozan et al., 2010), we tested these variables as potential confounders by adding them separately into the regression model with baseline serum BDNF as independent variable (note that dichotomous variables were coded as follows: season of sampling: $0=$ October-March, 1 = April-September; gender, 1 = male, 2 = female; use of antidepressants, $0=$ no, 1 = yes, fasting status (on the day of venipuncture), $0=$ no $1=$ yes). Covariates were retained in the model if addition of the covariate changed the beta of the independent variable with $>10 \%$. All regression models included the BDI-II score at baseline and frequency condition as a predictor to control for initial depression severity and the effect of treatment.

To investigate whether the prediction of serum BDNF or the Val66Met polymorphism on outcome was different between session frequency conditions, interactions (session frequency* serum BDNF and session frequency* Val66Met polymorphism; i.e., session frequency was already included as a main effect in each model to control for the effects of treatment) were added to the regression models for serum BDNF and Val66Met polymorphism, respectively. For testing the role of treatment modality, treatment modality (main effect) and interactions (treatment modality* serum BDNF and treatment modality * Val66Met polymorphism) were added to the final regression models for serum BDNF and Val66Met polymorphism, respectively.

Third, moderation by working memory was investigated by adding an interaction between serum BDNF or the Val66Met polymorphism and working memory into the regression models (i.e., the models without the interactions). Effects were tested at $p<.05$.

\subsection{Ethics statement}

The authors assert that all procedures contributing to this work comply with the ethical standards of the relevant national and institutional committees on human experimentation and with the Helsinki Declaration of 1975, as revised in 2008. All procedures involving human patients were approved by the Medical Ethical Committee of VU Medical Centre Amsterdam (registration number 2014.337).

\section{Results}

Of all participants for whom serum BDNF or the Val66Met polymorphism was analyzed $(n=150), 61.3 \%$ was female and the mean age at baseline was $38.82(S D=12.61) .26 .4 \%$ of the participants used antidepressants. The sample was severely depressed on average 
(baseline BDI-II: $33.88(S D=10)$. The extraction of the genotype of SNP rs6265 resulted in 73 individuals with Val/Val, 30 with Val/Met and 3 with Met/Met genotypes (minor allele frequency: 0.17). Patients with different genotypes did not differ in age $(F(2,103)=0.53, p=.58)$ or gender $(\chi=4.60, p=.10)$. Serum BDNF was $23.12(S D=7.2)$ and $23.26(S D=6.72)$ in the participants for whom serum BDNF was measured both at baseline and posttreatment. General descriptives of participants included in one of the analyses can be found in Table 1. Demographics and observed means $(S D)$ on all outcome measures at each time point for each sample and condition are given in data supplement 1. As shown in Table 2, serum BDNF at baseline correlated highly ( $r=0.61$ ) with serum BDNF posttreatment, but not with BDI-II scores at baseline or posttreatment.

\subsection{Change of serum BDNF during psychotherapy for depression}

Serum BDNF did not change over time, $F(1,71)=0.03, p=.86$. Change over time did not interact with baseline BDI-II scores, $F(1,71)=$ $0.01, p=.90$. Changes were not different between session frequency conditions, $F(1,71)=2.32, p=.13$, or between treatment modalities, $F$ $(1,71)=0, p=.99$.

\subsection{Baseline serum BDNF and the Val66Met polymorphism as predictors of psychotherapy outcome}

After controlling for relevant confounders, higher levels of serum BDNF at baseline were not significantly related to lower levels of depression at month $6, t(7,90)=-1.58, p=.11$. The Val66Met polymorphism was not significantly related to lower levels of depression at month $6, t(3,79)=-2.07, p=.42$. There were no significant interactions between treatment condition (session frequency or treatment modality) and serum BDNF at baseline or the Val66Met polymorphism on outcome. The final regression models (without interactions) can be found in Table 3. Differences in serum BDNF and the presence of Metalleles between responders and non-responders in are shown in Table 4. With mean baseline BDNF levels of $24.70 \mathrm{ng} / \mathrm{ml}$ in responders and $22.41 \mathrm{ng} / \mathrm{ml}$ in non-responders, these two groups did not differ significantly from each other $(p=.07)$. Groups did also not differ on posttreatment serum BDNF $(p=.87)$ or the presence of the Met-allele ( $p$ $=.85$ ).

\subsection{Working memory capacity as a moderator of the effect of serum $B D N F$ or the Val66Met polymorphism on depressive outcome}

Working memory capacity (WMC) significantly moderated the effect of baseline serum BDNF on the BDI-II score at month $6, t(9,65)=$ $-2.15, p=.03$ (see Table 5). WMC did not significantly moderate the effect of the Val66Met polymorphism on BDI-II at month $6, t(5,57)=$ $-0.74, p=.46$. To illustrate the direction of the effect of working

Table 1

General sample descriptives.

\begin{tabular}{ll}
\hline Demographics & \\
\hline Gender, $n(\%)$ female & $92(61.3)$ \\
Age, $M(S D)$ & $38.82(12.61)$ \\
Educational level & $16(10.7)$ \\
$\quad$ Low, $n(\%)$ & $73(48.7)$ \\
$\quad$ Medium, $n$ (\%) & $61(40.7)$ \\
$\quad$ High, $n$ (\%) & \\
Characteristics related to depression & \\
BDI-II baseline score & $33.88(10)$ \\
BDI-II posttreatment & $21.29(14.71)$ \\
Use of antidepressants, $n$ (\%) yes & $39(26.4)$ \\
Potential moderators & \\
Working memory: $n$-back & $64.55(19.16)$ \\
\hline
\end{tabular}

Table 2

Correlations between different measures of BDNF and levels of depression.

\begin{tabular}{|c|c|c|c|c|}
\hline & $\begin{array}{l}\text { Serum BDNF - } \\
\text { baseline }(n)\end{array}$ & $\begin{array}{l}\text { Serum BDNF - } \\
\text { month } 6(n)\end{array}$ & $\begin{array}{l}\text { BDI-II } \\
\text { baseline }(n)\end{array}$ & $\begin{array}{l}\text { BDI-II } \\
\text { month } 6 \\
(n)\end{array}$ \\
\hline $\begin{array}{l}\text { Serum BDNF } \\
\text {-baseline }(n)\end{array}$ & 1 & & & \\
\hline $\begin{array}{l}\text { Serum BDNF } \\
\text {-month } 6(n)\end{array}$ & $.61^{* *}(73)$ & 1 & & \\
\hline $\begin{array}{l}\text { BDI-II baseline } \\
\quad(n)\end{array}$ & $.03(138)$ & $.01(82)$ & 1 & \\
\hline $\begin{array}{l}\text { BDI-II month } 6 \\
\quad(n)\end{array}$ & $-.08(103)$ & $-.04(74)$ & $.44 * *(112)$ & 1 \\
\hline
\end{tabular}

Note. BDI-II = Beck Depression Inventory-II; BDNF = Brain derived neurotrophic factor. ${ }^{* *}=$ correlation is significant at $\mathrm{p}<.01$.

Table 3

Predicting depressive outcome (BDI-II score at month 6) with serum BDNF at baseline (model 1) or the Val66Met polymorphism (model 2).

\begin{tabular}{llllll}
\hline \multicolumn{1}{c}{$B$} & $S E$ & $t$ & $p$-value & $95 \% C I$ \\
\hline Model 1: BDNF serum $(n=98)$ & & & & \\
Intercept & -6.61 & 8.26 & -.80 & .42 & $-23.03 / 9.80$ \\
BDNF-serum baseline & -.32 & .20 & -1.58 & .11 & $-.73 / .08$ \\
BDI-II score baseline & .52 & .13 & 4.03 & $<.001$ &. $\mathbf{2 6 / . 7 8}$ \\
Age & .19 & .10 & 1.82 & .07 & $-.01 / .40$ \\
Female & $\mathbf{5 . 8 8}$ & $\mathbf{2 . 7 3}$ & $\mathbf{2 . 1 5}$ & .03 & $. \mathbf{4 5} / \mathbf{1 1 . 3 2}$ \\
Use of antidepressants & $\mathbf{6 . 3 7}$ & $\mathbf{2 . 8 5}$ & $\mathbf{2 . 2 4}$ & .03 & $. \mathbf{7 2} / \mathbf{1 2 . 0 4}$ \\
Fasting status & .83 & 2.87 & .29 & .77 & $-4.87 / 6.53$ \\
Frequency condition & -2.56 & 2.55 & -1 & .31 & $-7.63 / 2.51$ \\
& & & & & \\
Model 2: Val66Met polymorphism $(n=82)$ & & & \\
Intercept & 4.82 & 5.21 & .92 & .36 & $-5.55 / 15.20$ \\
Val66Met polymorphism & -2.07 & 2.55 & -.81 & .42 & $-7.14 / 3.01$ \\
BDI-II score baseline & .55 & .13 & $\mathbf{4 . 1 1}$ & $<.001$ & $. \mathbf{2 8} / .82$ \\
Frequency condition & -3.28 & 2.80 & -1.17 & .24 & $-8.85 / 2.29$ \\
\hline
\end{tabular}

Note. Note that variables were coded as follows: Val66Met polymorphism $=\mathrm{Val} /$ Val, $1=$ Val/Met, 2 = Met/Met, gender, $1=$ male, $2=$ female; use of antidepressants, $0=$ no, $1=$ yes, fasting status, $0=$ no (did eat), $1=$ yes (did not eat), frequency condition, $0=$ weekly, $1=$ twice weekly.

Table 4

Differences between responders and non-responders in serum BDNF and the presence of Met-alleles.

\begin{tabular}{llllll}
\hline & Response & $n$ & $\begin{array}{l}\text { Non- } \\
\text { response }\end{array}$ & $n$ & $\begin{array}{l}p \text { - } \\
\text { value }\end{array}$ \\
\hline $\begin{array}{l}\text { Serum BDNF - baseline, ng/ } \\
\quad \begin{array}{l}24.70 \\
\text { ml }\end{array}\end{array}$ & 46 & $22.41(6.45)$ & 57 & .07 \\
$\quad \begin{array}{l}\text { Serum BDNF - month 6, ng/ } \\
\quad \begin{array}{l}23.04 \\
\text { ml }\end{array}\end{array}$ & 33 & $22.77(6.88)$ & 41 & .87 \\
$\quad \begin{array}{l}\text { Presence of Met-allele, \% } \\
\quad \text { yes }\end{array}$ & 29.7 & 11 & 34.7 & 16 & .85 \\
\hline
\end{tabular}

Note. $\mathrm{BDNF}=$ Brain derived neurotrophic factor.

memory on the relation between baseline serum BDNF and depressive outcome, patients were assigned to a low WMC group when scoring below the mean and a high WMC group when scoring above the mean (WMC mean in the baseline serum BDNF group $=64.83, S D=19.20, n$ =96). As is shown in Fig. 2, high serum BDNF at baseline is related to lower BDI-II scores at month 6 in patients with high WMC (Pearson $r=$ $-0.35, p=.03, n=40$ ), but not in patients with low WMC (Pearson $r=$ $.17, p=.31, n=35)$. BDI-II scores at month 6 were lower for patients with a high WMC $(M=17.80, S D=13.05, n=40)$ compared to patients with a low WMC $(M=25.65, S D=14.18, n=35, t(73)=2.49, p=.01)$, but did not differ between patients with high ( $>$ mean) serum BDNF levels at baseline $(M=20.70, S D=15.38, n=41)$ versus patients with low ( $<$ mean) serum BDNF levels at baseline $(M=21.16, S D=12.24, n$ $=59, t(98)=0.16, p=.86)$. 
Table 5

Interaction between serum BDNF at baseline and working memory capacity ( $n=$ 75).

\begin{tabular}{|c|c|c|c|c|c|}
\hline & $B$ & $S E$ & $t$ & $\begin{array}{l}p \text { - } \\
\text { value }\end{array}$ & $95 \% C I$ \\
\hline Intercept & -30.75 & 20.74 & -1.48 & .14 & $\begin{array}{l}-72.18 / \\
10.68\end{array}$ \\
\hline Serum BDNF baseline & 1.23 & .77 & 1.59 & .11 & $-.31 / 2.78$ \\
\hline $\begin{array}{l}\text { Working memory capacity } \\
\text { (WMC) }\end{array}$ & .41 & .27 & 1.51 & .13 & $-.13 / .95$ \\
\hline $\begin{array}{l}\text { Serum BDNF baseline * } \\
\text { WMC }\end{array}$ & -.02 & .011 & -2.15 & .03 & $-.04 /-.002$ \\
\hline BDI-II score baseline & .48 & .14 & 3.34 & .001 & $.19 / .77$ \\
\hline Age & .15 & .11 & 1.25 & .21 & $-.08 / .38$ \\
\hline Female & 5.49 & 3.01 & 1.84 & .07 & $-.56 / 11.55$ \\
\hline Use of antidepressants & 2.74 & 3.13 & .87 & .38 & $-3.52 / 9.01$ \\
\hline Fasting status & 3.08 & 3.34 & .92 & .36 & $-3.59 / 9.76$ \\
\hline Frequency condition & .61 & 2.74 & .22 & .82 & $-4.86 / 6.09$ \\
\hline
\end{tabular}

Note. WMC $=$ working memory capacity; Note that variables were coded as follows: gender, $1=$ male, $2=$ female; use of antidepressants, $0=$ no, $1=$ yes, fasting status, $0=$ no (did eat), $1=$ yes (did not eat), frequency condition, $0=$ weekly, 1 = twice weekly.

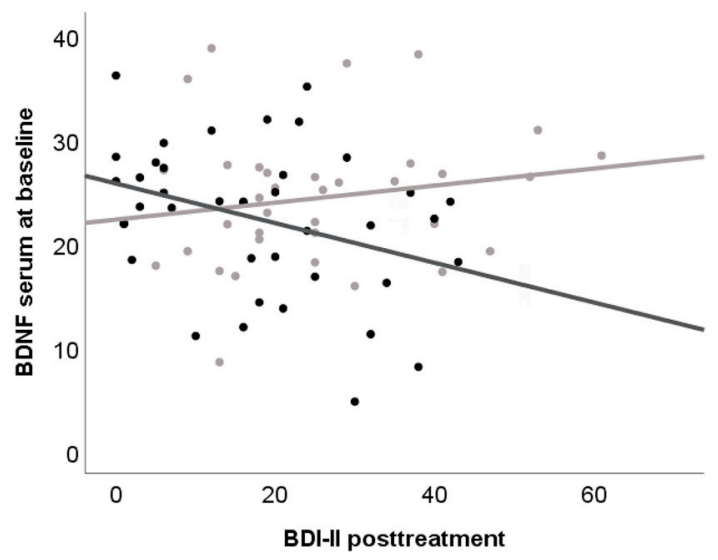

Fig. 2. Interaction between serum BDNF at baseline and working memory capacity on depression (BDI-II score) at month 6 . Black line $=$ high working memory capacity (score $>64.83$ ), grey line $=$ low working memory capacity (score $<64.83$ ).

\section{Discussion}

The present study investigated the role of brain-derived neurotrophic factor (BDNF) (serum levels and genetic polymorphism) in relation to change and outcome in cognitive behavioral therapy (CBT) and interpersonal psychotherapy (IPT) for depression. Serum BDNF levels did not change during psychotherapy and changes did not significantly differ between session frequencies (once versus twice weekly) or treatment modalities (CBT versus IPT). Baseline serum BDNF and the Val66Met polymorphism were not significantly associated with outcomes after 6 months and also this association did not differ between treatment conditions. Working memory moderated the relation between baseline serum BDNF and outcome: higher baseline serum BDNF was related to lower posttreatment levels of depression, but only in the patients with high working memory.

In line with the three other studies on the role of BDNF in psychotherapy for depression (Bakker et al., 2014; da Silva et al., 2018; Koch et al., 2009; Rayner et al., 2019), our findings suggested that BDNF levels on average do not play a role in the effects of psychotherapy for depression. Our findings contrast the other studies that found a relation between response to CBT and BDNF (Fullana et al., 2012; Kobayashi et al., 2005) in the treatment of anxiety disorders. It is possible that the role of BDNF differs between populations (i.e., depression versus anxiety), but also the limitations of a small sample size may explain this discrepancy.

The finding that baseline serum BDNF levels were related to depressive outcome in the patients with high levels of working memory is in line with the findings of LeMoult (2014). That study particularly showed that in participants who were identified as Met-carriers, lower working memory capacity was associated with increased symptoms of depression over time. However, in the present study there was no relation between baseline serum BDNF and depressive outcome in patients with low working memory, but in the patients with high working memory. Differences between study populations may explain this discrepancy in findings. It is possible that although in individuals with subclinical depression (LeMoult et al., 2014), low BDNF and lower working memory capacity relates to an increase of depression over time, in a sample with severe levels of depression (our study) both high BDNF and working memory capacity are necessary in order to reduce depressive symptoms. Our results may suggest that there is a subgroup of depressive patients where learning processes such as working memory and BDNF levels are important in predicting treatment outcome, while for another subgroup they are not. Also, as moderators can help to identify mechanisms of change (Kazdin, 2007), our findings may point to different pathways of change for these different subgroups of patients.

What are the potentially different pathways of change these subgroups might follow? One suggestion is that patients with higher learning processes at baseline may be better able to improve through the more cognitive part of CBT, cognitive change (Lorenzo-Luaces et al., 2015), while those patients with lower learning processes may benefit from more direct CBT techniques, such as behavioral activation (Dimidjian et al., 2011). However, future research is necessary to find out whether patients with different learning processes at baseline, both measured at a biological and cognitive level, may benefit from different pathways of change (Bruijniks et al., 2019). In addition, studies should investigate whether learning processes are equally important in different forms of psychotherapy: while CBT has a clear skill-based approach (Barber and DeRubeis, 2001; Strunk et al., 2007), it is less clear how learning processes may play a role in IPT. Last, as those individuals with more impairments in the learning processes also had slightly higher BDI-II scores posttreatment, targeting the impairments in the learning processes in these individuals might be an opportunity to improve psychotherapy outcome (for an example: see Harvey et al., 2017).

A strength of the present study was the relatively large sample size compared to earlier studies (da Silva et al., 2018; Kobayashi et al., 2005; Koch et al., 2009). In addition, because of the large variation in participating treatment centers and inclusion of many therapists with varying educational backgrounds, external validity is considered high (Bruijniks et al., 2020). A limitation of the present study was that the sample was severely depressed on average, making it difficult to generalize these results to patients with less severe levels of depression. Also, although the present sample size was relatively large compared to earlier trials that investigated the role of BDNF in psychotherapy, the sample size was still rather limited to identify moderators (Brookes et al., 2004). Thus, especially the interaction we found between working memory and serum BDNF demands replication.

Future studies should target the heterogeneity of previous findings by finding out whether BDNF plays a (different) role in the treatment of different psychopathologies, and investigate the role of BDNF in relation to working memory on depressive outcome in samples with larger variation in levels of depression at baseline. Also, both biological and psychological measures of learning processes at baseline should be included in future psychotherapy trials. As earlier studies pointed to an interaction between BDNF and COMT on working memory performance in healthy populations, it would be interesting for future studies to see whether the COMT plays a similar role in an psychotherapeutic setting (Chen et al., 2016; Nagel et al., 2008). With more data available, individual participant data meta analyses (Debray et al., 2015; Riley et al., 
Data supplement 1

Sample characteristics: analyzed participants with serum BDNF measurements both at baseline and posttreatment ( $n=73$ ), participants with a serum BDNF measurement at baseline $(n=138)$ and participants with the Val66Met polymorphism $(n=106)$.

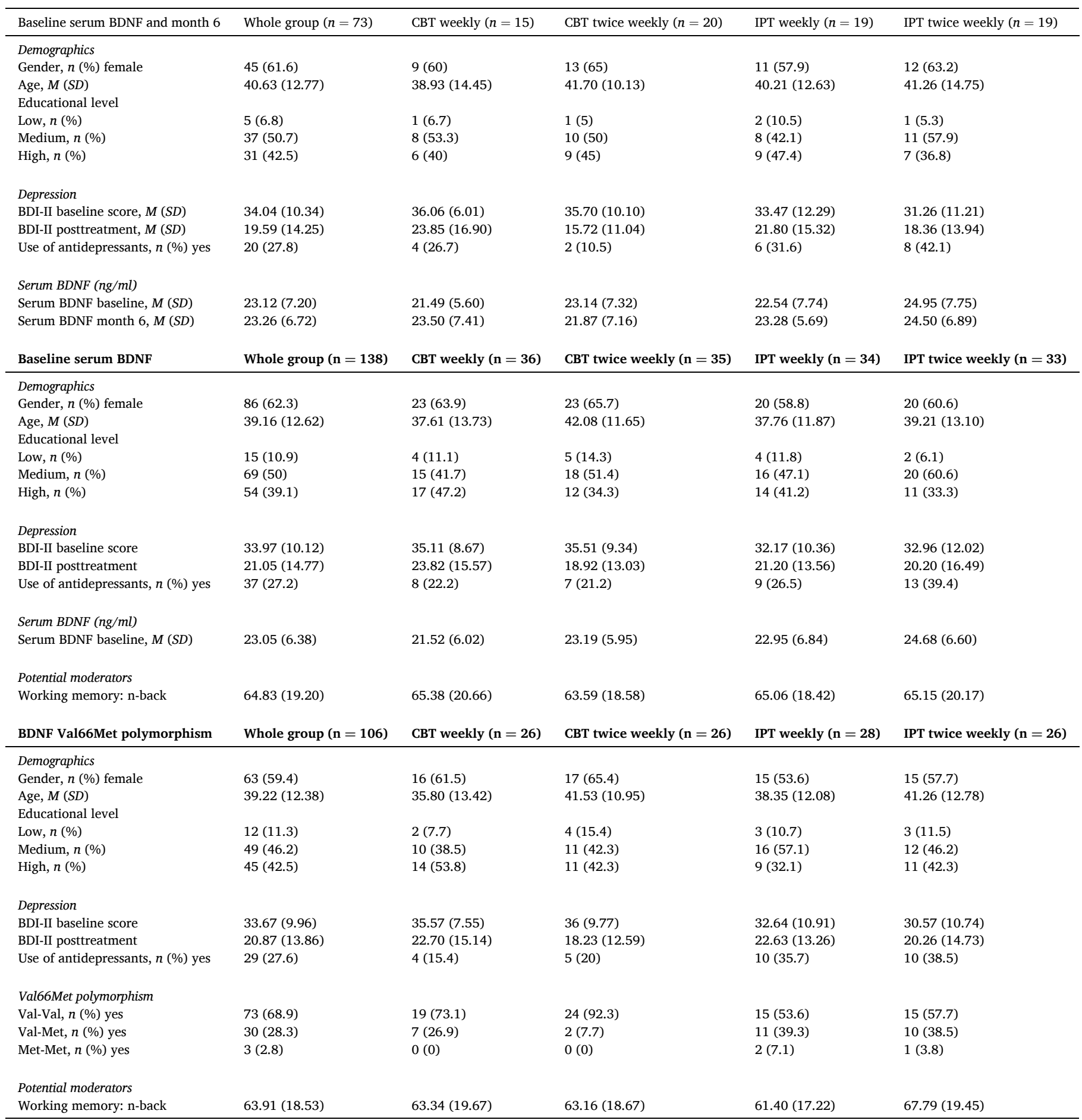

Note. $\mathrm{BDNF}=$ Brain derived neurotrophic factor; BDI-II = Beck Depression Inventory-II. Note that there were missings at BDI-II scores posttreatment (serum BDNF baseline and month 6: 1 for CBT weekly 2 for CBT twice weekly 4 for IPT weekly; Serum BDNF baseline: 8 for CBT weekly, 9 for CBT twice weekly, 14 for IPT weekly, 4 IPT for twice weekly; BDNF Val66Met polymorphism: 6 for CBT weekly, 5 for CBT twice weekly, 9 for IPT weekly, 3 IPT for twice weekly), use of antidepressants (Serum BDNF baseline and month 6: 1 for CBT twice weekly; Serum BDNF baseline: 2 for CBT twice weekly; BDNF Val66Met polymorphism: 1 for CBT twice weekly), working memory (Serum BDNF baseline: 11 for CBT weekly, 13 for CBT twice weekly, 9 for IPT weekly, 9 IPT for twice weekly; BDNF Val66Met polymorphism: 7 for CBT weekly, 8 for CBT twice weekly, 7 for IPT weekly, 7 IPT for twice weekly). 
2010) might be an option to investigate moderators within a larger sample size.

In conclusion, higher serum BDNF at baseline was related to lower posttreatment depression, but only in patients with high working memory. These findings, if replicated, might indicate that while BDNF may not be related to psychotherapy outcomes in general, they may play a role in the presence of specific learning processes such as working memory capacity.

\section{Funding}

This study was funded by ZonMw (project number: 837002401) and Stichting tot Steun VCVGZ (project number: 234). The funders were not involved in the study design; the collection, analysis and interpretation of data; the writing of the report or the decision to submit the article for publication.

\section{Declaration of competing interest}

The authors declare that they have no known competing financial interests or personal relationships that could have appeared to influence the work reported in this paper.

\section{Acknowledgements}

We acknowledge the contribution of participating patients and therapists at Altrecht, GGZ inGeest, GGZ Oost-Brabant, Pro Persona, PsyQ Amsterdam, PsyQ Den Haag, PsyQ Haarlem, PsyQ Leiden and Riagg Maastricht. Without their cooperation the trial would have been impossible to conduct. Furthermore, we gratefully thank the participating hospitals (Amsterdam Universitair Medisch Centrum; Leids Universitair Medisch Centrum; Lab West, Den Haag; Radboud Universitair Medisch Centrum, Nijmegen, Maastricht Universitair Medisch Centrum+, Universitair Medisch Centrum Utrecht). We also thank Danielle Tilburgs, Nicole Billingy, Kris Wijma and. Sofie Jansen for their assistance during the data collection.

\section{Appendix A. Supplementary data}

Supplementary data to this article can be found online at https://doi. org/10.1016/j.jpsychires.2020.07.045.

\section{References}

Adler, A.D., Strunk, D.R., Fazio, R.H., 2015. What changes in Cognitive Therapy for depression? An examination of cognitive therapy skills and maladaptive beliefs. Behav. Ther. 46, 96-109. https://doi.org/10.1016/j.beth.2014.09.001.

Aldoghachi, A.F., Tor, Y.S., Redzun, S.Z., Bin Lokman, K.A., Abdul Razaq, N.A., Shahbudin, A.F., Badamasi, I.M., Cheah, P.S., Stanslas, J., Veerakumarasivam, A., Rosli, R., Ibrahim, N., Lye, M.S., Ling, K.H., 2019. Screening of brain-derived neurotrophic factor (BDNF) single nucleotide polymorphisms and plasma BDNF levels among Malaysian major depressive disorder patients. PloS One 14, 1-19. https://doi.org/10.1371/journal.pone.0211241.

Azeredo, L.A. de, De Nardi, T., Levandowski, M.L., Tractenberg, S.G., KommersMolina, J., Wieck, A., Irigaray, T.Q., Silva Filho, I.G. da, Grassi-Oliveira, R., 2017. The brain-derived neurotrophic factor (BDNF) gene Val66Met polymorphism affects memory performance in older adults. Rev. Bras. Psiquiatr. 39, 90-94. https://doi. org/10.1590/1516-4446-2016-1980.

Bakker, J.M., Lieverse, R., Menne-Lothmann, C., Viechtbauer, W., Pishva, E., Kenis, G., Geschwind, N., Peeters, F., Van Os, J., Wichers, M., 2014. Therapygenetics in mindfulness-based cognitive therapy: do genes have an impact on therapy-induced change in real-life positive affective experiences. Transl. Psychiatry 4 . https://doi. org/10.1038/tp.2014.23 e384-10.

Balaratnasingam, S., Janca, A., 2012. Brain Derived Neurotrophic Factor: a novel neurotrophin involved in psychiatric and neurological disorders. Pharmacol. Ther. 134, 116-124. https://doi.org/10.1016/j.pharmthera.2012.01.006.

Barber, J.P., DeRubeis, R.J., 2001. Change in compensatory skills in cognitive therapy for depression. J. Psychother. Pract. Res. 10, 8-13.

Barth, J., Munder, T., Gerger, H., Nüesch, E., Trelle, S., Znoj, H., Jüni, P., Cuijpers, P., 2013. Comparative efficacy of seven psychotherapeutic interventions for patients with depression: a network meta-analysis. PLoS Med. 10 https://doi.org/10.1371/ journal.pmed.1001454.
Beck, A.T., Steer, R.A., Brown, G.K., 1996. Beck Depression Inventory-II: Manual. Harcourt Brace, Boston.

Beck, A.T., Steer, R.A., Carbin, M.G., 1988. Psychometric properties of the Beck depression inventory: twenty-five years of evaluation. Clin. Psychol. Rev. 8, 77-100. https://doi.org/10.1016/0272-7358(88)90050-5.

Beevers, C.G., 2005. Cognitive vulnerability to depression: a dual process model. Clin. Psychol. Rev. 25, 975-1002. https://doi.org/10.1016/j.cpr.2005.03.003.

Braver, T.S., Cohen, J.D., Nystrom, L.E., Jonides, J., Smith, E.E., Noll, D.C., 1997. A parametric study of prefrontal cortex involvement in human working memory. Neuroimage 5, 49-62. https://doi.org/10.1006/nimg.1996.0247.

Brookes, S.T., Whitely, E., Egger, M., Smith, G.D., Mulheran, P.A., Peters, T.J., 2004. Subgroup analyses in randomized trials: risks of subgroup-specific analyses; power and sample size for the interaction test. J. Clin. Epidemiol. 57, 229-236. https://doi. org/10.1016/j.jclinepi.2003.08.009.

Brooks, S.J., Nilsson, E.K., Jacobsson, J.A., Stein, D.J., Fredriksson, R., Lind, L., Schiöth, H.B., 2014. BDNF polymorphisms are linked to poorer working memory performance, reduced cerebellar and hippocampal volumes and differences in prefrontal cortex in a Swedish elderly population. PloS One 9. https://doi.org/ 10.1371/journal.pone.0082707.

Bruijniks, S.J.E., Bosmans, J., Peeters, F.P.M.L., Hollon, S.D., van Oppen, P., van den Boogaard, M., Dingemanse, P., Cuijpers, P., Arntz, A., Franx, G., Huibers, M.J.H., 2015. Frequency and change mechanisms of psychotherapy among depressed patients: study protocol for a multicenter randomized trial comparing twice-weekly versus once-weekly sessions of CBT and IPT. BMC Psychiatr. 15 https://doi.org/ 10.1186/s12888-015-0532-8.

Bruijniks, S.J.E., DeRubeis, R.J., Hollon, S.D., Huibers, M.J.H., 2019. The potential role of learning capacity in cognitive behavior therapy for depression: a systematic review of the evidence and future directions for improving therapeutic learning. Clin. Psychol. Sci. 7, 668-692. https://doi.org/10.1177/2167702619830391.

Bruijniks, S.J., Lemmens, L.H., Hollon, S.D., Peeters, F.P., Cuijpers, P., Arntz, A., Van Den Boogaard, M., 2020. The effects of once-versus twice-weekly sessions on psychotherapy outcomes in depressed patients. Br. J. Psychiatr. 216 (4), 222-230.

Brunoni, A.R., Lopes, M., Fregni, F., 2008. A systematic review and meta-analysis of clinical studies on major depression and BDNF levels: implications for the role of neuroplasticity in depression. Int. J. Neuropsychopharmacol. 11, 1169-1180. https://doi.org/10.1017/S1461145708009309.

Burgess, N., Maguire, E.A., Keefe, J.O., 2002. The Human Hippocampus and Spatial and Episodic Memory 35, 625-641. https://doi.org/10.1016/S0896-6273(02)00830-9.

Bus, B.A.A., Molendijk, M.L., Penninx, B.J.W.H., Buitelaar, J.K., Kenis, G., Prickaerts, J., Elzinga, B.M., Voshaar, R.C.O., 2011. Determinants of serum brain-derived neurotrophic factor. Psychoneuroendocrinology 36, 228-239. https://doi.org/ 10.1016/j.psyneuen.2010.07.013.

Chen, W., Chen, C., Xia, M., Wu, K., Chen, C., He, Q., Xue, G., Wang, W., He, Y., Dong, Q., 2016. Interaction effects of BDNF and COMT genes on resting-state brain activity and working memory. Front. Hum. Neurosci. 10, 1-13. https://doi.org/10.3389/ fnhum.2016.00540.

Cohen, Z.D., DeRubeis, R.J., 2018. Treatment Selection in Depression 1-28. https://doi. org/10.1146/annurev-clinpsy-050817-084746.

Cuijpers, P., Karyotaki, E., Weitz, E., Andersson, G., Hollon, S.D., van Straten, A., 2014. The effects of psychotherapies for major depression in adults on remission, recovery and improvement: a meta-analysis. J. Affect. Disord. 159, 118-126. https://doi.org/ 10.1016/j.jad.2014.02.026.

Cuijpers, P., Sijbrandij, M., Koole, S.L., Andersson, G., Beekman, A.T., Reynolds, C.F., 2013. The efficacy of psychotherapy and pharmacotherapy in treating depressive and anxiety disorders: a meta-analysis of direct comparisons. World Psychiatr. 12, 137-148. https://doi.org/10.1002/wps.20038.

da Silva, S.K., Wiener, C., Ghisleni, G., Oses, J.P., Jansen, K., Molina, M.L., Silva, R., Souza, L.D., 2018. Effects of cognitive-behavioral therapy on neurotrophic factors in patients with major depressive disorder. Rev. Bras. Psiquiatr. 361-366. https://doi. org/10.1590/1516-4446-2017-2357.

Debray, T.P.A., Moons, K.G.M., van Valkenhoef, G., Efthimiou, O., Hummel, N., Groenwold, R.H.H., Reitsma, J.B., 2015. Get real in individual participant data (IPD) meta-analysis: a review of the methodology. Res. Synth. Methods 6, 293-309. https://doi.org/10.1002/jrsm.1160.

Dimidjian, S., Barrera, M., Martell, C., Muñoz, R.F., Lewinsohn, P.M., 2011. The origins and current status of behavioral activation treatments for depression. Annu. Rev. Clin. Psychol. 7, 1-38. https://doi.org/10.1146/annurev-clinpsy-032210-104535.

Dobson, K.S., Hollon, S.D., Dimidjian, S., Schmaling, K.B., Kohlenberg, R.J., Gallop, R.J., Rizvi, S.L., Gollan, J.K., Dunner, D.L., Jacobson, N.S., 2008. Randomised trial of behavioural activation, cognitive therapy, and antidepressant medication in the prevention of relapse and recurrence in major depression. J. Consult. Clin. Psychol. 76, 468-477. https://doi.org/10.1037/0022-006X.76.3.468.

Dranovsky, A., Hen, R., 2006. Hippocampal neurogenesis: regulation by stress and antidepressants. Biol. Psychiatr. 59, 1136-1143. https://doi.org/10.1016/j. biopsych.2006.03.082.

Fullana, M.A., Alonso, P., Gratacòs, M., Jaurrieta, N., Jiménez-Murcia, S., Segalàs, C., Real, E., Estivill, X., Menchón, J.M., 2012. Variation in the BDNF Val66Met polymorphism and response to cognitive-behavior therapy in obsessive-compulsive disorder. Eur. Psychiatr. 27, 386-390. https://doi.org/10.1016/j. eurpsy.2011.09.005.

Goodman, J.B., Freeman, E.E., Chalmers, K.A., 2019. The relationship between early life stress and working memory in adulthood: a systematic review and meta-analysis. Memory 27, 868-880. https://doi.org/10.1080/09658211.2018.1561897.

Harvey, A.G., Dong, L., Lee, J.Y., Gumport, N.B., Hollon, S.D., RabeHesketh, S., Hein, K., Haman, K., McNamara, M.E., Weaver, C., Martinez, A., Notsu, H., Zieve, G., Armstrong, C.C., 2017. Can integrating the Memory Support Intervention into 
cognitive therapy improve depression outcome? Study protocol for a randomized controlled trial. Trials 18, 539. https://doi.org/10.1186/s13063-017-2276-x.

Harvey, A.G., Lee, J., Williams, J., Hollon, S.D., Walker, M.P., Thompson, M.A., Smith, R., 2014. Improving outcome of psychosocial treatments by enhancing memory and learning. Perspect. Psychol. Sci. 9, 161-179. https://doi.org/10.1177/ 1745691614521781.

International Genome Sample Resource IGSR, 2019.

Kanter, J.W., Manos, R.C., Bowe, W.M., Baruch, D.E., Busch, A.M., Rusch, L.C., 2010. What is behavioral activation?. A review of the empirical literature. Clin. Psychol. Rev. 30, 608-620. https://doi.org/10.1016/j.cpr.2010.04.001.

Kazdin, A.E., 2007. Mediators and mechanisms of change in psychotherapy research. Annu. Rev. Clin. Psychol. 3, 1-27. https://doi.org/10.1146/annurev. clinpsy.3.022806.091432.

Kishi, T., Yoshimura, R., Ikuta, T., Iwata, N., 2018. Brain-derived neurotrophic factor and major depressive disorder: evidence from meta-analyses. Front. Psychiatr. 8, 1-5. https://doi.org/10.3389/fpsyt.2017.00308.

Kobayashi, K., Shimizu, E., Hashimoto, K., Mitsumori, M., Koike, K., Okamura, N., Koizumi, H., Ohgake, S., Matsuzawa, D., Zhang, L., Nakazato, M., Iyo, M., 2005. Serum brain-derived neurotrophic factor (BDNF) levels in patients with panic disorder: as a biological predictor of response to group cognitive behavioral therapy. Prog. Neuro-Psychopharmacol. Biol. Psychiatry 29, 658-663. https://doi.org/ 10.1016/j.pnpbp.2005.04.010.

Koch, J.M., Hinze-Selch, D., Stingele, K., Huchzermeier, C., Göder, R., SeeckHirschner, M., Aldenhoff, J.B., 2009. Changes in CREB Phosphorylation and BDNF plasma levels during Psychotherapy of depression. Psychother. Psychosom. 78, 187-192. https://doi.org/10.1159/000209350.

Lam, M., Awasthi, S., Watson, H.J., Goldstein, J., Panagiotaropoulou, G., Trubetskoy, V., Karlsson, R., Frei, O., Fan, C.-C., De Witte, W., Mota, N.R., Mullins, N., Brügger, K., Lee, H., Wray, N., Skarabis, N., Huang, H., Neale, B., Daly, M., Mattheissen, M., Walters, R., Ripke, S., 2019. RICOPILI: rapid imputation for COnsortias PIpeLIne. Bioinformatics 7-11. https://doi.org/10.1093/bioinformatics/btz633.

Lane, R.D., Ryan, L., Nadel, L., Greenberg, L., 2015. Memory reconsolidation, emotional arousal, and the process of change in psychotherapy: new insights from brain science. Behav. Brain Sci. 38, e1. https://doi.org/10.1017/S0140525X14000041.

LeMoult, J., Carver, C.S., Johnson, S.L., Joormann, J., 2014. Predicting change in symptoms of depression during the transition to university: the roles of BDNF and working memory capacity. Cognit. Affect Behav. Neurosci. 15, 95-103. https://doi. org/10.3758/s13415-014-0305-8.

Lorenzo-Luaces, L., Keefe, J.R., DeRubeis, R.J., 2016. Cognitive-behavioral therapy: Nature and relation to non-cognitive behavioral therapy. Behav. Ther. 47 (6), 785-803.

Mikoteit, T., Hemmeter, U., Eckert, A., Brand, S., Bischof, R., Delini-Stula, A., et al., 2015. Improved alertness is associated with early increase in serum brain-derived neurotrophic factor and antidepressant treatment outcome in major depression. Neuropsychobiology 72 (1), 16-28.

Molendijk, M.L., Bus, B.A., Spinhoven, P., Penninx, B.W.J.H., Kenis, G., Prickaerts, J., Voshaar, R.O., Elzinga, B.M., 2011. Serum levels of brain-derived neurotrophic factor in major depressive disorder: state-trait issues, clinical features and pharmacological treatment. Mol. Psychiatr. 16, 1088-1095. https://doi.org/ 10.1038/mp.2010.98.

Molendijk, M.L., Haffmans, J.P.M., Bus, B.A.A., Spinhoven, P., Penninx, B.W.J.H., Prickaerts, J., Voshaar, R.C.O., Elzinga, B.M., 2012. Serum BDNF concentrations show strong seasonal variation and correlations with the amount of ambient sunlight. PloS One 7, 1-7. https://doi.org/10.1371/journal.pone.0048046.

Nagel, I.E., Chicherio, C., Li, S.C., von Oertzen, T., Sander, T., Villringer, A., Heekeren, H R., Bäckman, L., Lindenberger, U., 2008. Human aging magnifies genetic effects on executive functioning and working memory. Front. Hum. Neurosci. 2, 1-8. https:// doi.org/10.3389/neuro.09.001.2008.

National Institute for Health and Care Excellence, 2009. Depression in adults: recognition and management. Clinical guideline [CG90]. Retrieved from. https:// www.nice.org.uk/guidance/cg90/resources/depression-in-adults-recognition-an d-management-pdf-975742636741.

Notaras, M., Hill, R., Van Den Buuse, M., 2015. The BDNF gene Val66Met polymorphism as a modifier of psychiatric disorder susceptibility: progress and controversy. Mol. Psychiatr. 20, 916-930. https://doi.org/10.1038/mp.2015.27.

Ozan, E., Okur, H., Eker, Ç., Eker, Ö.D., Gönül, A.S., Akarsu, N., 2010. The effect of depression, BDNF gene val66met polymorphism and gender on serum BDNF levels. Brain Res. Bull. 81, 61-65. https://doi.org/10.1016/j.brainresbull.2009.06.022. PerkinElmer, n.d. Chemagen chemagic.

Perroud, N., Salzmann, A., Prada, P., Nicastro, R., Hoeppli, M.E., Furrer, S., Ardu, S., Krejci, I., Karege, F., Malafosse, A., 2013. Response to psychotherapy in borderline personality disorder and methylation status of the BDNF gene. Transl. Psychiatry 3, e207-e208. https://doi.org/10.1038/tp.2012.140.

Polyakova, M., Stuke, K., Schuemberg, K., Mueller, K., Schoenknecht, P., Schroeter, M.L., 2015. BDNF as a biomarker for successful treatment of mood disorders: a systematic \& quantitative meta-analysis. J. Affect. Disord. 174, 432-440. https://doi.org/ 10.1016/j.jad.2014.11.044.

Rayner, C., Coleman, J.R.I., Purves, K.L., Hodsoll, J., Goldsmith, K., Alpers, G.W., Andersson, E., Arolt, V., Boberg, J., Bögels, S., Creswell, C., Cooper, P., Curtis, C., Deckert, J., Domschke, K., El Alaoui, S., Fehm, L., Fydrich, T., Gerlach, A.L., Grocholewski, A., Hahlweg, K., Hamm, A., Hedman, E., Heiervang, E.R., Hudson, J. L., Jöhren, P., Keers, R., Kircher, T., Lang, T., Lavebratt, C., Sang-hyuck, L., Lester, K. J., Lindefors, N., Margraf, J., Nauta, M., Pané-Farré, C.A., Pauli, P., Rapee, R.M., Reif, A., Rief, W., Roberts, S., Schalling, M., Schneider, S., Silverman, W.K., Ströhle, A., Teismann, T., Thastum, M., Wannemüller, A., Weber, H., Wittchen, H.U., Wolf, C., Rück, C., Breen, G., Eley, T.C., 2019. A genome-wide association metaanalysis of prognostic outcomes following cognitive behavioural therapy in individuals with anxiety and depressive disorders. Transl. Psychiatry 9 (1), 1-13. https://doi.org/10.1038/s41398-019-0481-y.

Riedel, M., Möller, H.J., Obermeier, M., Schennach-Wolff, R., Bauer, M., Adli, M., Kronmüller, K., Nickel, T., Brieger, P., Laux, G., Bender, W., Heuser, I., Zeiler, J., Gaebel, W., Seemüller, F., 2010. Response and remission criteria in major depression - a validation of current practice. J. Psychiatr. Res. 44, 1063-1068. https://doi.org/ 10.1016/j.jpsychires.2010.03.006.

Riley, R.D., Lambert, P.C., Abo-Zaid, G., 2010. Meta-analysis of individual participant data: rationale, conduct, and reporting. BMJ 340, 521-525. https://doi.org/ 10.1136/bmj.c221.

Santacana, M., Arias, B., Mitjans, M., Bonillo, A., Montoro, M., Rosado, S., Guillamat, R., Vallès, V., Pérez, V., Forero, C.G., Fullana, M.A., 2016. Predicting response trajectories during cognitive-behavioural therapy for panic disorder: No association with the BDNF gene or childhood maltreatment. PloS One 11, 1-14. https://doi.org/ 10.1371/journal.pone.0158224.

Schmidt, I.D., Pfeifer, B.J., Strunk, D.R., 2019. Putting the cognitive back in cognitive therapy: sustained cognitive change as a mediator of in-session insights and depressive symptom improvement. J. Consult. Clin. Psychol. 87, 446-456. https:// doi.org/10.1037/ccp0000392.

Sen, S., Duman, R., Sanacora, G., 2008. Serum BDNF, depression and anti-depressant medications: meta-analyses and implications. Biol. Psychiatr. 64, 527-532. https:// doi.org/10.1016/j.biopsych.2008.05.005.Serum.

Simon, G.E., Perlis, R.H., 2010. PERSONALIZED medicine for depression conceptual model for personalized treatment: what evidence is relevant? Am. J. Psychiatr. 167, 1445-1455.

Snyder, H.R., 2013. Major depressive disorder is associated with braod impairments on neuropsychological measures of evecutive function: a meta-analysis and review. Psychol. Bull. 139, 81-132. https://doi.org/10.1037/a0028727.Major.

Strunk, D.R., DeRubeis, R.J., Chiu, A.W., Alvarez, J., 2007. Patients' competence in and performance of cognitive therapy skills: relation to the reduction of relapse risk following treatment for depression. J. Consult. Clin. Psychol. 75, 523-530. https:// doi.org/10.1037/0022-006X.75.4.523.

The 1000 Genomes Project Consortium, 2012. An integrated map of genetic variation from 1.092 human genomes. Nature 491, 56-65. https://doi.org/10.1038/ nature11632.

U.S. National Library of Medicine, 2019. rs6265.

van der Does, A.J.W., 2002. BDI-II-NL. In: Handleiding. De Nederlandse versie van de Beck Depression. Publ. Invent. Ed. Lisse Harcourt Test.

Wagner, S., Kayser, S., Engelmann, J., Schlicht, K.F., Dreimüller, N., Tüscher, O., MüllerDahlhaus, F., Braus, D.F., Tadić, A., Neyazi, A., Frieling, H., Lieb, K., 2018. Plasma brain-derived neurotrophic factor (pBDNF) and executive dysfunctions in patients with major depressive disorder. World J. Biol. Psychiatr. 1-12. https://doi.org/ 10.1080/15622975.2018.1425478, 0.

World Health Organization, 2017. Depression and other common mental disorders: global health estimates. World Heal. Organ 1-24. CC.BY/NC/SA.3.0.IGO.

Zhao, M., Chen, L., Yang, J., Han, D., Fang, D., Qiu, X., Yang, X., Qiao, Z., Ma, J., Wang, L., Jiang, S., Song, X., Zhou, J., Zhang, J., Chen, M., Qi, D., Yang, Y., Pan, H., 2017. BDNF Val66Met polymorphism, life stress and depression: a meta-analysis of gene-environment interaction. J. Affect. Disord. 227, 226-235. https://doi.org/ 10.1016/j.jad.2017.10.024.

Zou, Y.F., Ye, D.Q., Feng, X.L., Su, H., Pan, F.M., Liao, F.F., 2010. Meta-analysis of BDNF Val66Met polymorphism association with treatment response in patients with major depressive disorder. Eur. Neuropsychopharmacol 20, 535-544. https://doi.org/ 10.1016/j.euroneuro.2009.12.005. 